\title{
Review Article \\ Exercise Protects Bone after Stroke, or Does It? A Narrative Review of the Evidence
}

\author{
Karen Borschmann \\ Florey Neuroscience Institutes, 245 Burgundy Street, Heidelberg VIC 3084, Australia \\ Correspondence should be addressed to Karen Borschmann, karenb@unimelb.edu.au \\ Received 9 June 2011; Revised 27 July 2011; Accepted 15 August 2011 \\ Academic Editor: Gillian Mead
}

Copyright () 2012 Karen Borschmann. This is an open access article distributed under the Creative Commons Attribution License, which permits unrestricted use, distribution, and reproduction in any medium, provided the original work is properly cited.

Physical inactivity contributes to accelerated bone loss after stroke, leading to heightened fracture risk, increased mortality, and reduced independence. This paper sought to summarise the evidence for the use of physical activity to protect bone in healthy adults and adults with stroke, and to identify international recommendations regarding any means of bone protection after stroke, in order to guide rehabilitation practice and future research. A search was undertaken, which identified 12 systematic reviews of controlled trials which investigated the effect of physical activity on bone outcomes in adults. Nine reviews included healthy adults and three included adults with stroke. Twenty-five current international stroke management guidelines were identified. Highimpact loading exercise appears to have a site-specific effect on the microarchitecture of healthy postmenopausal women, and physical activity has a small effect on enhancing or maintaining bone mineral density in chronic stroke patients. It is not known whether this translates to reduce fracture risk. Most guidelines included recommendations for early mobilisation after stroke and falls prevention. Two recommendations were identified which advocated exercise for the prevention bone loss after stroke, but supporting evidence was limited. Research is required to determine whether targeted physical activity can protect bone from early after stroke, and whether this can reduce fracture risk.

\section{Introduction}

Stroke-related impairments and inactivity contribute to the accelerated development of osteoporosis [1-3]. Combined with a high rate of falls [4-6], stroke survivors are particularly vulnerable to fall-related injuries, especially fractures. The risk of fracture after stroke is 1.5- to fourfold compared to age-matched controls [7], and fractures after stroke reduce the ability to regain independent walking and increase mortality [8].

Bone maintains its strength through the modulation of its remodelling activity (bone turnover), adapting its structural and material properties in response to its loading environment [9]. Loads on bone are generated by ground reaction forces and muscle activity. Immobility from hemiplegia or extended bed rest decreases loads and thus contributes to increased removal of bone [10]. Conversely, during adulthood, mechanical loading of bone can contribute to maintenance of bone strength by maintaining bone mass, and vigorous high-impact loading may have a small capacity to increase bone mass [10].

Physical activity levels are often very low among acute stroke patients $[11,12]$, who may spend over half of the day ( $8 \mathrm{am}$ to $5 \mathrm{pm}$ ) resting in bed [12]. Prolonged bed rest, however, leads to rapid loss of bone [13]. Urinary markers of bone resorption (C-telopeptide and $\mathrm{N}$-telopeptide), which can be used to predict hip fracture in older women [14], were elevated by $17.8 \%$ and $28.7 \%$, respectively, after one day of bed-rest in healthy men aged 25.5 years (SD 2.9) [13]. In addition, reductions in bone mineral density (BMD) at the tibia of up to $3 \%$ have been observed in a similar group of young men after five weeks of bed rest [15]. In comparison, the normal rate of bone loss in healthy men and women aged over 60 years is approximately $1 \%$ per year [16-18].

The period of immobility after stroke appears to strongly influence the amount of bone which is lost. People who remained nonambulant for one year after stroke lost up to $13 \%$ of femoral neck BMD of the paretic limb [19]. In 
contrast, people who relearned to walk within two months, and people who walked from the first week after stroke showed losses of $8 \%$ and $3 \%$, respectively [19]. Other stroke-induced impairments also appear to contribute to the amount of bone loss: severity of impairment $[20,21]$, disuse of paretic limbs [22], reduction in weight bearing [20], reduced muscle mass [23], muscle weakness [24], and reduced cardio-respiratory fitness [23].

Evidence supports the role of targeted physical activity for maintaining or improving BMD in healthy women and men aged over 60 years, in whom bone loss is occurring $[25,33]$. High-impact loading exercise has a modest, positive, and site-specific effect in healthy postmenopausal women, primarily enhancing cortical, rather than trabecular, bone mass and geometry [29]. National guidelines recommend physical activity for the prevention of osteoporosis in the healthy adult population [36]. Moreover, physical activity is recommended to improve mobility and function [37], muscle strength [38, 39], and fitness [40] after stroke, and early and frequent mobilisation is recommended for the prevention of complications in acute stroke patients [41]. In addition, some evidence suggests that physical activity may maintain or improve bone density in chronic stroke [42]. However, despite the prevalence and detrimental effects of bone loss after stroke, and the potential for physical activity to modulate bone structure and density, recently updated Australian clinical guidelines for stroke management [41] did not mention bone loss. Evidence from healthy adults contributes to our understanding of bone loss after stroke; however, separate evaluations are warranted, since the generalisability of results from healthy adults to adults with stroke may be limited due to stroke-related impairments and neurovascular changes. The aims of this paper were to summarise the evidence for the use of physical activity to protect bone in both healthy adults and adults with stroke. A secondary aim was to summarise international recommendations regarding any means of bone protection after stroke.

\section{Method}

A search was undertaken in order to retrieve all systematic reviews, of controlled trials that investigated physical activity interventions and contained bone-related outcomes in healthy adult or adult stroke populations. The following electronic databases were searched from 2001 on 31 May 2011: Ageline, Allied and Complimentary Medicine (AMED), Cochrane Library, Cumulative Index to Nursing and Allied Health Literature (CINAHL), Embase, Medline, Physiotherapy Evidence Database (PEDro), PsycINFO, SPORTDiscus, and Web of Knowledge. Keywords used to identify reviews included "bone, bone loss, fracture, or osteoporosis" combined with "physical activity, exercise or loading." International stroke management guidelines were identified in these databases using terms "stroke" and "management, guideline, or consensus statement." Additionally, stroke association websites and colleagues with content knowledge were consulted to identify systematic reviews and clinical guidelines. Non-English language guidelines were identified in the described search and were included in subsequent drafts of the manuscript once colleagues were available to translate.

The identified systematic reviews were summarised for included trials, conclusions, and recommendations for future research, and this information is contained on Table 1. The identified stroke management guidelines were searched for key terms of "bone, fracture, or osteoporosis," and recommendations were reviewed for content regarding bone protection, physical activity, exercise, and falls prevention. Summaries of these recommendations and their levels of evidence are recorded on Table 2. Appendices A and B contain descriptions of classifications of levels of evidence and grades of recommendations.

\section{Results}

3.1. Physical Activity for the Prevention of Bone Loss in Healthy Adult Populations. Nine systematic reviews of controlled trials which investigated the use of exercise as an intervention against bone loss in healthy adults were identified. One review investigated adults with low bone mineral density [30], one investigated premenopausal women [68], five studied postmenopausal women $[25,26,28,29,31]$, and two $[32,33]$ included adults of all age groups. Interventions were based on various forms of physical activity which were hypothesised to reduce bone loss through weight bearing and muscular action on bone. Outcomes were two dimensional measurement of bone mass of spine, hip, wrist, or total body, using dual-energy X-ray absorptiometry (DXA), or three-dimensional bone mass and bone architecture, measured with peripheral quantitative computerised tomography (pQCT).

There were mixed results regarding the effect of impact (weight bearing) and nonimpact (resistance training, aerobics) exercises on BMD of pre- and postmenopausal women's lumbar spine $[25,26,28,31,68]$, femoral neck $[26,31]$, whole hip [25, 28, 68], and wrist [25]. Bone mineral density was reported to be improved by weight-bearing aerobic exercise with or without muscle strengthening exercise, when the duration of the intervention was at least a year [30]. Exercise appeared to positively influence site-specific bone mass and geometry in postmenopausal women, with the most prominent changes being in response to high-impact loading exercise. Exercise was reported to be able to reduce falls, fallrelated fractures, and several risk factors for falls in individuals with low BMD [30]. Most authors commented on the heterogeneity of interventions and research quality. Recommendations were made for the design of future studies including high-quality methodology, larger sample sizes, periods of intervention greater than one year, targeted exercise programs, and consistent methods and sites of outcome measurement. It was reported that research was needed to determine whether improvements in bone mass and geometry were capable of preventing fractures. 


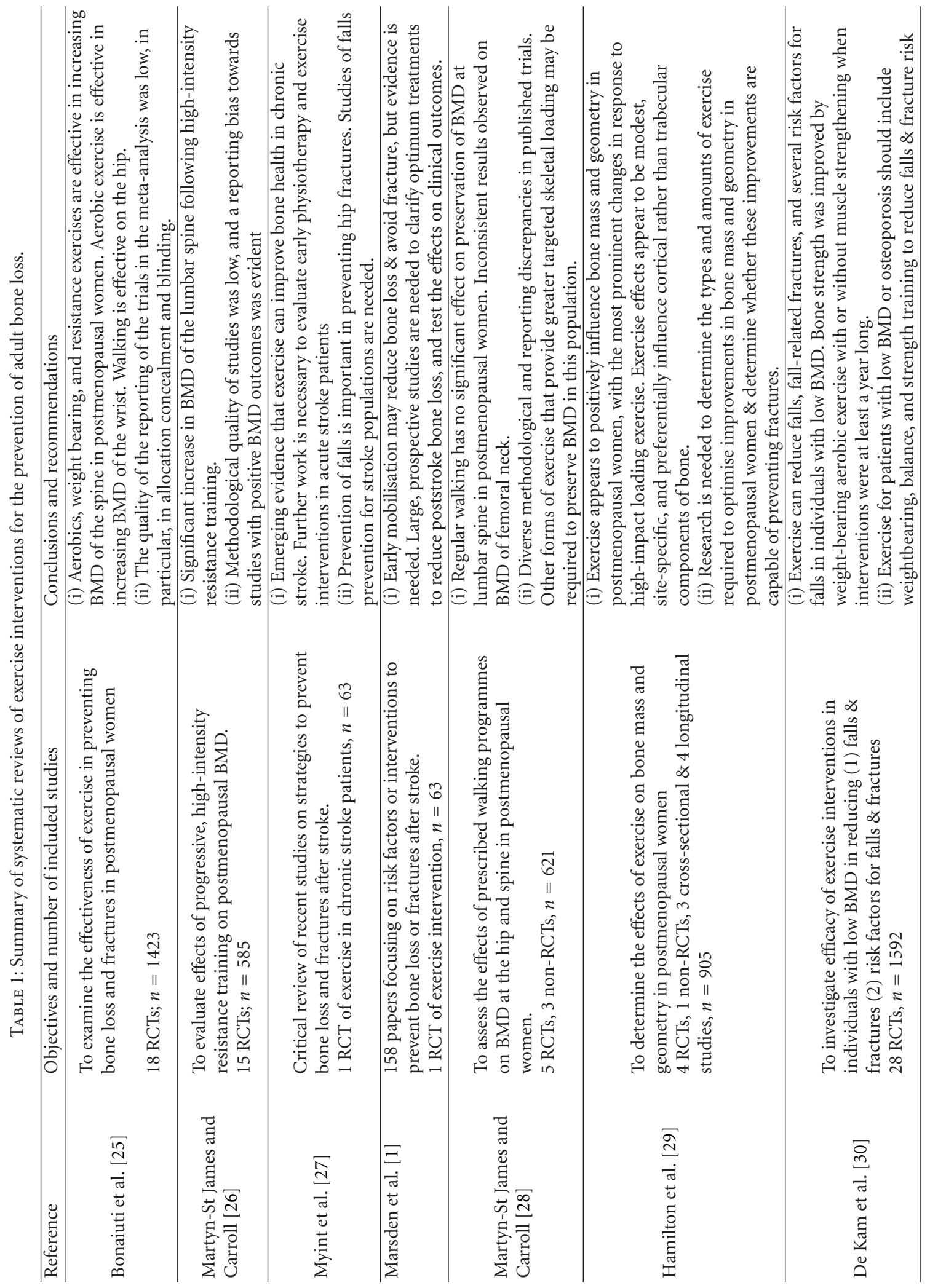




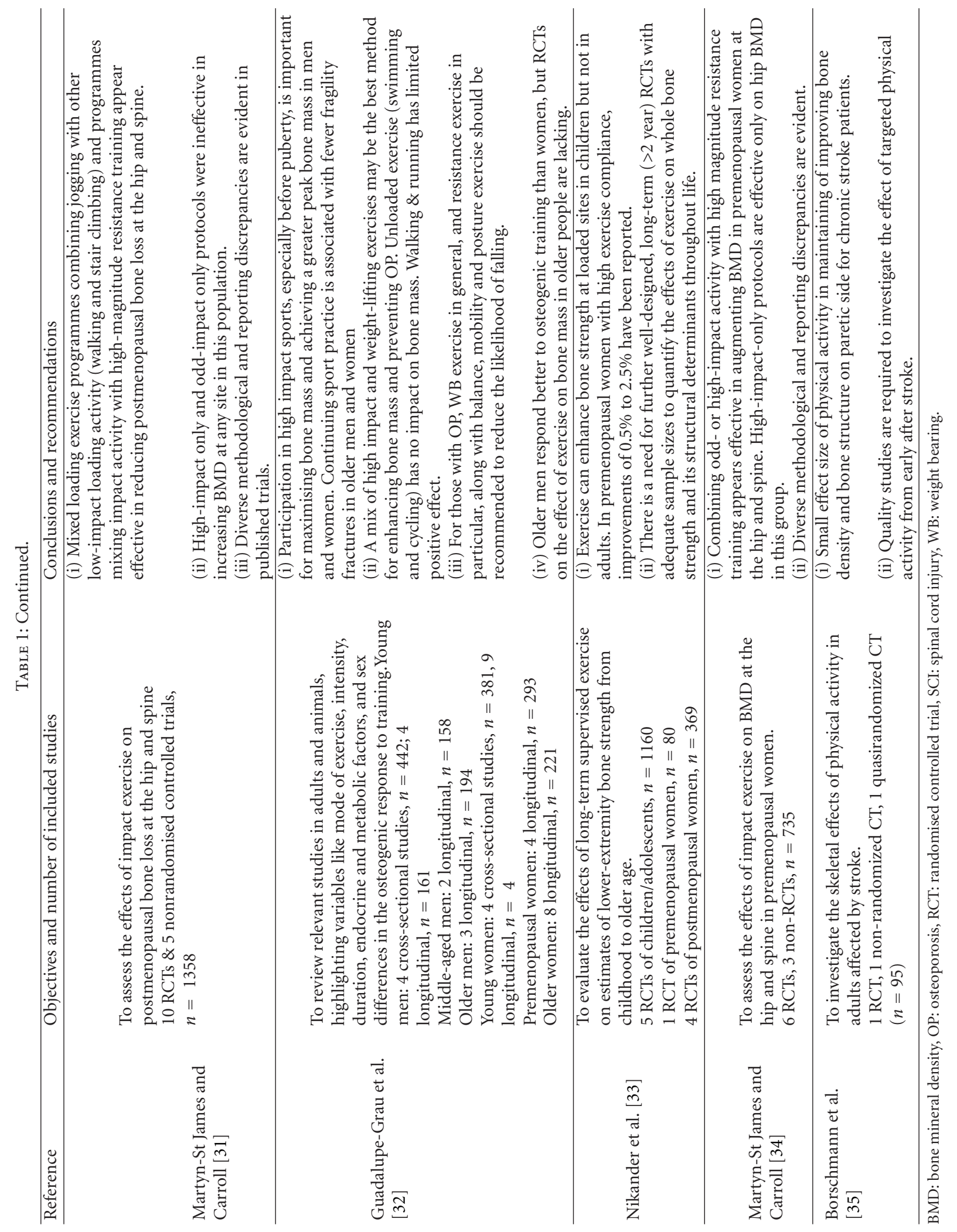




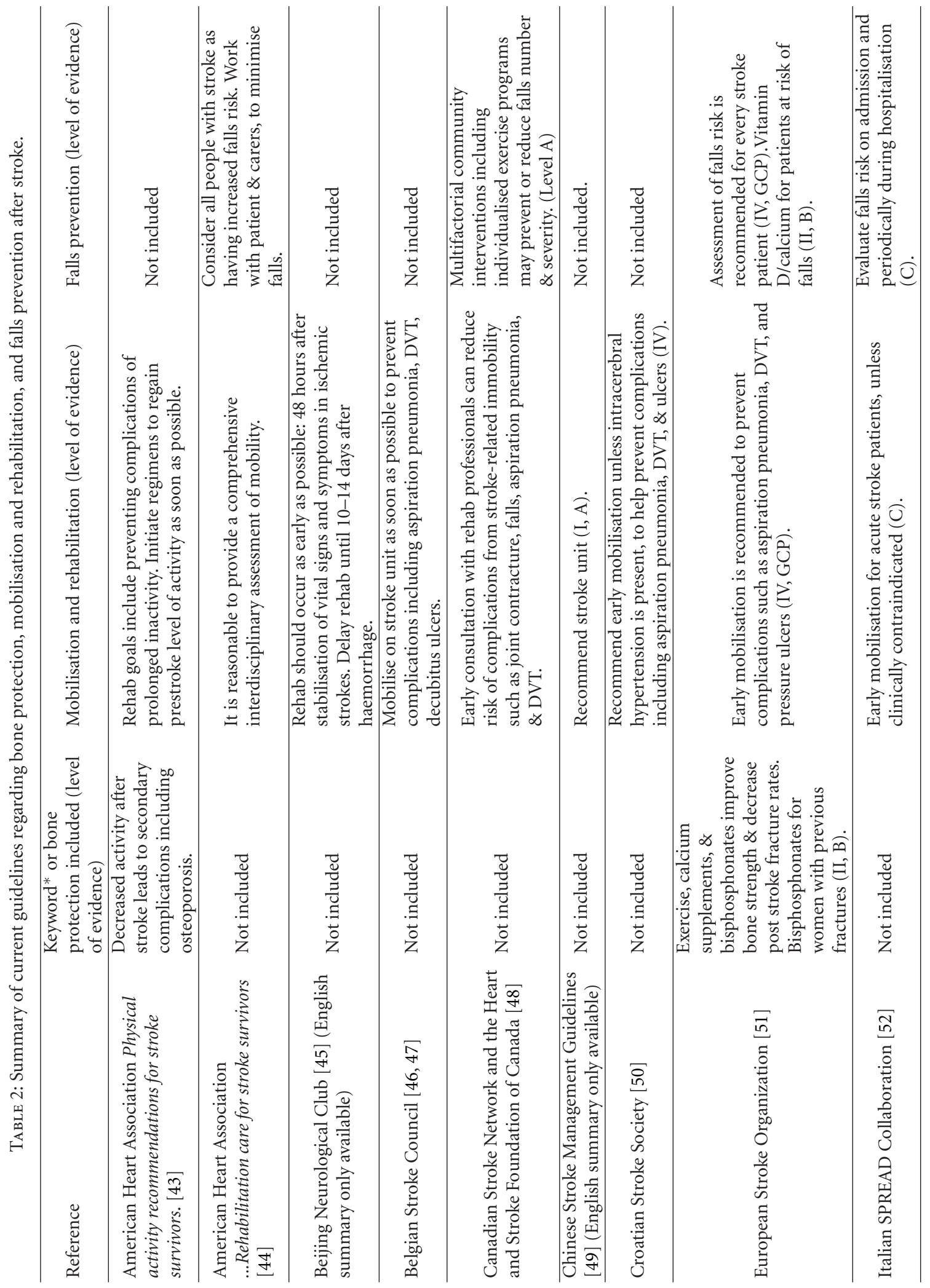




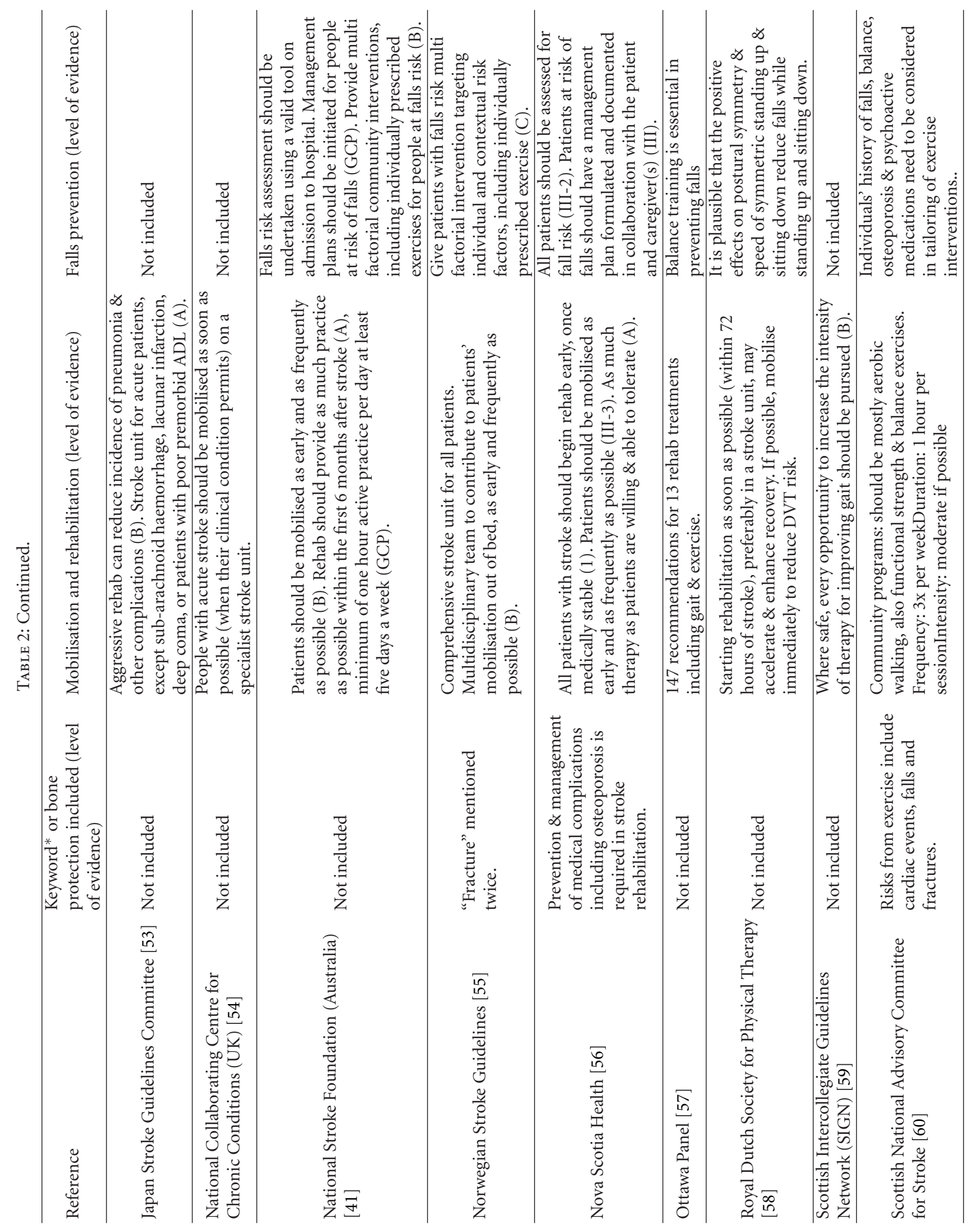




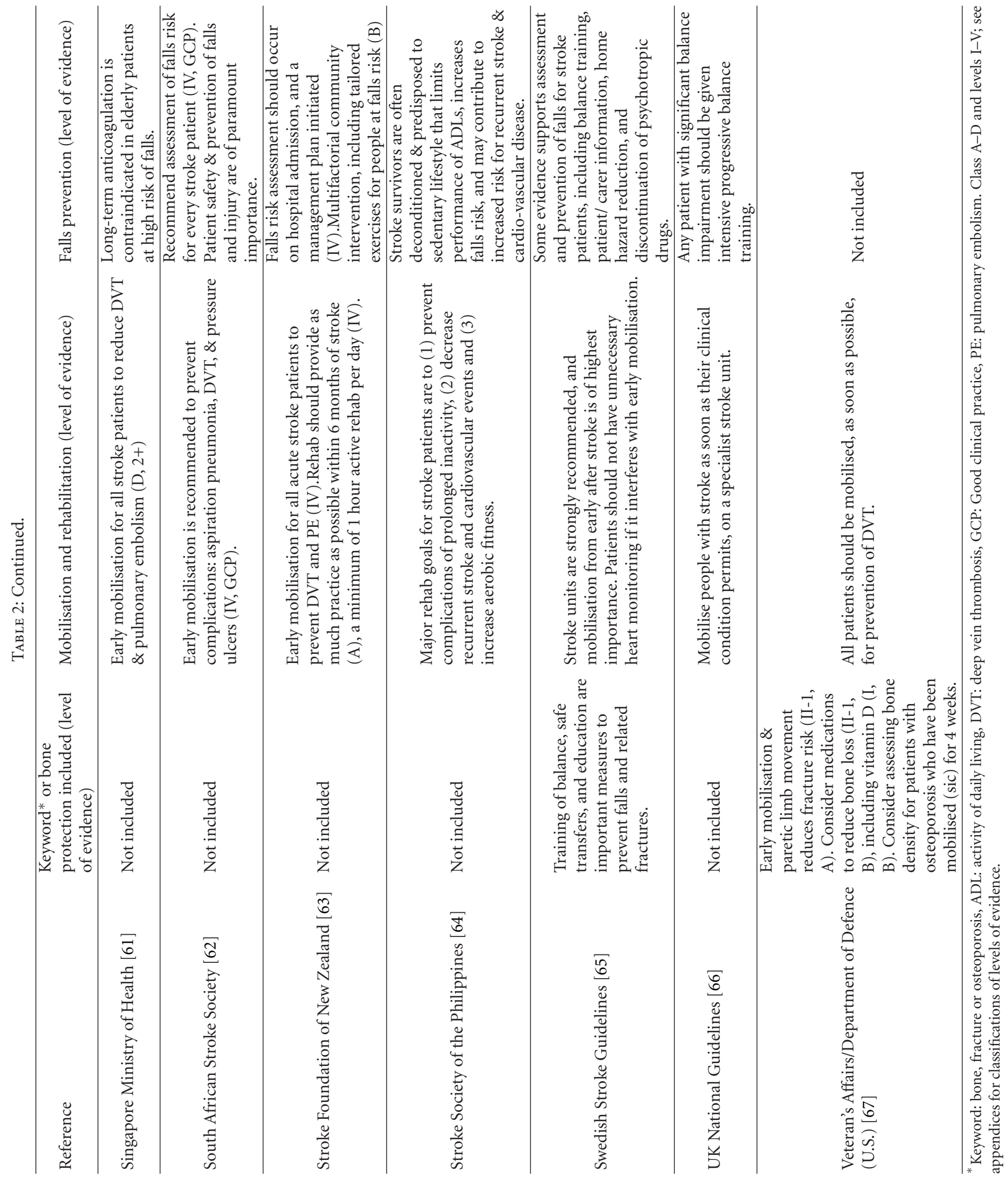


3.2. Physical Activity for the Prevention of Bone Loss in Adults with Stroke. Three systematic reviews of controlled trials which investigated the use of physical activity as an intervention against poststroke bone loss were identified [ 1 , $27,35]$, and these reviews described three controlled trials. One trial $[42,69]$ investigated people who were approximately 5 years after stroke. This study found beneficial effects on tibial bone architecture, and maintenance of paretic hip BMD, as a result of a 19-week exercise intervention. Marsden et al. [1] reported that although the study was level " $A$ " evidence due to its being a randomised trial, the sample size was small $(n=63)$ and was biased toward a younger male population. Marsden et al. [1] concluded "...early mobilization may reduce bone loss and avoid fracture, but evidence is needed...", which reflects the conclusion of Myint et al. [27] "Further work is necessary to evaluate early physiotherapy and exercise interventions in acute stroke patients..." Two further trials which included chronic stroke patients were identified by Borschmann et al. [35]. One was a low-quality trial [70] which found no effect on upper limb BMD with an intervention of ball squeezing for a duration of one-to-three years. The other trial [71] observed a small positive on enhancing tibial bone cortical thickness with six months of twice weekly body-weight supported treadmill training. Borschmann et al. concluded that although the number of studies was limited, results demonstrated a small effect of physical activity in maintaining or improving bone density and bone structure on the paretic side in chronic stroke patients. Quality studies are required to investigate the effect of targeted physical activity interventions to minimize bone loss after stroke.

3.3. International Recommendations Regarding Bone Protection after Stroke. Twenty-five international stroke management guidelines were identified [41, 43-60, 62, 64-67, 72]. Seven guidelines $[43,51,55,56,60,65,67]$ contained one or more keywords "bone, fracture, or osteoporosis." Almost all guidelines included recommendations for physical activity after stroke, and most contained recommendations for falls prevention. Two guidelines $[51,67]$ contained comments regarding the use of physical activity for bone protection after stroke, one [67] which contained a chapter regarding poststroke osteoporosis.

The European Stroke Organisation's stroke management guideline [51] contained the statement "Exercise, calcium supplements, and bisphosphonates improve bone strength and decrease fracture rates in stroke patients. .." However, the supporting reference [73] did not provide evidence for the use of exercise to improve bone strength or decrease fracture rates. The US Veteran's Affairs guideline [48] contained a chapter on osteoporosis after stroke, including the recommendation "Early mobilization and movement of the paretic limbs will reduce the risk of bone fracture after stroke..." Three supporting references were supplied for this recommendation. Two references were the literature reviews previously described $[1,27]$, and the third reference was a narrative review by Beaupre and Lew [74] which included 18 longitudinal or cross-sectional studies which investigated bone density changes after stroke. Beaupre et al [74] reported that “...it is beginning to be recognized that improvements in performing the activities of daily living. .. will also benefit the patient by helping to preserve bone mass and thereby reducing the risk of hip fracture...," in reference to a drug trial by Ikai et al. [75]. In the control group of this trial, people who had higher activity of daily living (ADL) function were observed to experience less bone loss over three months, compared to people who had lower ADL. Although the trial did not use an intervention based on ADL training, Ikai et al. concluded "ADL is related to the progression of osteoporosis for women with hemiplegia and that increasing the level of ADL (will) lead to decrease the progression of osteoporosis...."

\section{Discussion}

Despite well-documented bone loss, increased fracture risk, and poor outcomes after fracture in people with stroke [19, 77], only seven of the 25 international stroke management guidelines identified in this search contained a keyword "bone, fracture, or osteoporosis." Many of the guidelines provided information on falls prevention, which is likely to reduce fracture rate, and the use of pharmacological bone protection was advocated. Targetted exercise appears to enhance site-specific bone architecture in healthy postmenopausal women, and there is limited evidence to support the use of physical activity to enhance bone mineralisation and architecture in chronic stroke patients. If physical activity from early after stroke can prevent bone loss, then current recommendations for early mobilisation may provide skeletal benefits. However, the safety of early mobilisation is still being investigated. Recommendations should take this into consideration, given their potential to change practice.

Although more research is required, it appears that physical activity has the capacity to maintain or improve bone-related outcomes in both the healthy and stroke adult populations. Healthy adults have an approximate annual bone loss of $1 \%$. Healthy adult participants without reported activity limitations, who were included in the trials reported in this paper, were observed to have enhanced BMD when the intervention duration was at least a year. Moreover, exercise appears to positively influence site-specific bone geometry in postmenopausal women, with the most prominent changes in response to high-impact loading exercise. In contrast, in the trials which included people with chronic stroke who were able to walk at least $10 \mathrm{~m}$, and who had potentially lost $15 \%$ of BMD in the first year after stroke, small effect sizes were observed in hip BMD, with just 23 weeks of physical activity intervention. It is possible that in people with higher rates of bone loss (stroke patients compared to healthy adults), a shorter duration of intervention is required to observe the effects of interventions. However, it is not clear whether these skeletal improvements (bone mineralisation and bone geometry) reduce fracture risk.

Coupled with bone fragility, falls are an important component of fracture risk for people with stroke [27]. De Kam et al. (2009) reported that exercise for people with low BMD or osteoporosis should include weight-bearing, 
TABle 3: Principles of exercise to maximise bone adaptation.

\begin{tabular}{lll}
\hline Exercise principle & More effective & Less effective \\
\hline Weight bearing & $\begin{array}{l}\text { (i) High impact (jogging, jumping) } \\
\text { (ii) Bursts of activity } \\
\text { (iii) Rapid movement }\end{array}$ & $\begin{array}{l}\text { (i) Low impact (walking) } \\
\text { (ii) Sustained activity } \\
\text { (iii) Slow movement } \\
\text { (iv) Non-weight-bearing aerobic (swimming or cycling) does } \\
\text { not enhance bone density } \\
\text { (i) Light weight }\end{array}$ \\
Resistance training & $\begin{array}{l}\text { (i) Heavy weight } \\
\text { (ii) Rapid lifting (power training) } \\
\text { (i) Target muscle connected to } \\
\text { buscle groups }\end{array}$ & $\begin{array}{l}\text { (ii) Slow lift (traditional resistance training) } \\
\text { fracture (hip, wrist, spine) } \\
\text { (i) Short bouts interspersed with } \\
\text { rest breaks } \\
\text { (i) Novel force patterns (change in } \\
\text { direction or height of jumps) }\end{array}$ \\
Length of training & $\begin{array}{l}\text { (i) Non-specific-muscle groups } \\
\text { (i) Continuous movement }\end{array}$ \\
\hline
\end{tabular}

Adapted from http://www.osteoporosis.org.au/images/stories/documents/internal/oa_exercise_gphp.pdf.

TABLE 4: Levels of evidence for intervention studies.

\begin{tabular}{|c|c|}
\hline Level of evidence & Type of evidence \\
\hline $1++$ & High-quality meta-analyses, systematic reviews of RCTs, or RCTs with a very low risk of bias. \\
\hline $1+$ & Well-conducted meta-analyses, systematic reviews of RCTs, or RCTs with a low risk of bias. \\
\hline $1-$ & Meta-analyses, systematic reviews of RCTs, or RCTs with a high risk of bias.* \\
\hline $2++$ & $\begin{array}{l}\text { High-quality systematic reviews of case-control or cohort studies. High-quality case-control or cohort } \\
\text { studies with a very low risk of confounding, bias orchance and a high probability that the relationship is } \\
\text { causal. }\end{array}$ \\
\hline $2+$ & $\begin{array}{l}\text { Well-conducted case-control or cohort studies with a low risk of confounding, bias orChance, and a } \\
\text { moderate probability that the relationship is causal. }\end{array}$ \\
\hline $2-$ & $\begin{array}{l}\text { Case control or cohort studies with a high risk of confounding, bias or chance, and asignificant risk that } \\
\text { the relationship is not causal.* }\end{array}$ \\
\hline 3 & Nonanalytic studies (e.g., case reports and case series). \\
\hline 4 & Expert opinion, formal consensus. \\
\hline
\end{tabular}

balance, and strength training to reduce falls and fracture risk. Most stroke management guidelines identified in this review recommended falls risk assessment and individualised management for all stroke patients. Level A evidence was presented in the guidelines to recommend mobility training for people with stroke who have difficulty walking [41] and individually tailored exercise programs for communitybased falls prevention $[44,48]$. Multifactorial falls prevention programs were recommended within the hospital environment, but supporting evidence for this was low $[41,59]$.

Until further research into poststroke bone loss is undertaken to guide the ongoing development of recommendations for protection of bone, it would be prudent to incorporate principles of bone adaptation into individually tailored stroke rehabilitation programs. Individual tailoring of programs for people with stroke should consider falls risk, mobility, potential low bone mass, ability to follow commands, and other stroke impairments. High impact exercises may not be practical or safe for people with stroke impairments and possible osteoporosis, but any weightbearing activity provides greater loading on bone than bed rest. Guidelines for healthy adults [36] report that although there is a lack of evidence regarding the optimal prescription of exercise to prevent fracture, evidence-based principles of exercise to maximise bone adaptation have been developed (Table 3).

The body of literature regarding the use of exercise to modulate bone loss in adults demonstrates the large international interest in this important area of research. However, there are many gaps in the literature regarding the skeletal effect of physical activity, particularly in the stroke population. Only three intervention trials $[42,69,71]$ which investigated the skeletal effects of physical activity in people with stroke were reported in any of the 25 international stroke guidelines and 12 systematic reviews identified in this review. There is an urgent need to develop the international research agenda regarding bone loss after stroke, in order to reduce fracture risk and its devastating outcomes after stroke. 
TABLE 5: Gradings of recommendations.

\begin{tabular}{ll}
\hline Grade & Description \\
\hline Level A & Body of evidence can be trusted to guide practice \\
Level B & Body of evidence can be trusted to guide practice in most situations \\
Bevel C & $\begin{array}{l}\text { Body of evidence provides some support for recommendations(s), but care } \\
\text { should be taken in its application }\end{array}$ \\
Level D & Body of evidence is weak, and recommendation must be applied with caution \\
$\begin{array}{l}\text { Good clinical practice } \\
\text { (GCP) points }\end{array}$ & Recommended best practice based on clinical experience and expert opinion \\
\hline
\end{tabular}

National Health and Medical Research Council, NHMRC additional levels of evidence and grades for recommendations for developers of guidelines. 2008-2010 [78].

\section{Conclusion}

Weight-bearing exercise and avoidance of bed rest have the potential to prevent bone loss after stroke. Bone loss appears to be rapid after stroke, but evidence regarding the timing and magnitude of bone loss is required, in order to determine the most beneficial timing of interventions. High-quality studies of over two year's duration, with adequate sample sizes and consistent outcome measurement, are required to determine whether targeted skeletal loading exercise, mobilisation, and avoidance of bed rest, from early after stroke are able to reduce bone loss and fracture risk. This information will support the ongoing development of international stroke management guidelines to guide rehabilitation practice and improve outcomes for people with stroke.

\section{Appendices}

\section{A.}

For more details, see Table 4.

\section{B.}

For more details, see Table 5.

\section{Acknowledgments}

Thanks are due to Assoc. Prof. Julie Bernhardt for her constructive comments on a draft of the manuscript, and Dr Sandra Iuliano-Burns and Assoc. Prof Marco Pang for previous advice. Many thanks go to Dr Torunn Askim, Prof Thomas Linden, Ms Teddy Oosterhuis, and Dr Wenwen Zhang for providing translated summaries of stroke management guidelines. Thanks are due to the Victorian State Government for operational infrastructure support.

\section{References}

[1] J. Marsden, L. M. Gibson, C. E. Lightbody, A. K. Sharma, M. Siddiqi, and C. Watkins, "Can early onset bone loss be effectively managed in post-stroke patients? An integrative review of the evidence," Age and Ageing, vol. 37, no. 2, pp. 142150, 2008.
[2] L. Jorgensen and B. K. Jacobsen, "Changes in muscle mass, fat mass, and bone mineral content in the legs after stroke: a 1 year prospective study," Bone, vol. 28, no. 6, pp. 655-659, 2001.

[3] M. Liu, T. Tsuji, Y. Higuchi, K. Domen, K. Tsujiuchi, and N. Chino, "Osteoporosis in hemiplegic stroke patients as studied with dual-energy x-ray absorptiometry," Archives of Physical Medicine and Rehabilitation, vol. 80, no. 10, pp. 1219-1226, 1999.

[4] N. Kerse, V. Parag, V. L. Feigin et al., "Falls after stroke: results from the auckland regional community stroke (ARCOS) study, 2002 to 2003," Stroke, vol. 39, no. 6, pp. 1890-1893, 2008.

[5] A. Forster and J. Young, "Incidence and consequences of falls due to stroke: a systematic inquiry," British Medical Journal, vol. 311, no. 6997, pp. 83-86, 1995.

[6] F. Batchelor, K. Hill, S. MacKintosh, and C. Said, "What works in falls prevention after stroke?: a systematic review and metaanalysis," Stroke, vol. 41, no. 8, pp. 1715-1722, 2010.

[7] M. S. Dennis, K. M. Lo, M. McDowall, and T. West, "Fractures after stroke: frequency, types, and associations," Stroke, vol. 33, no. 3, pp. 728-734, 2002.

[8] A. Ramnemark, M. Nilsson, B. Borssén, and Y. Gustafson, "Stroke, a major and increasing risk factor for femoral neck fracture," Stroke, vol. 31, no. 7, pp. 1572-1577, 2000.

[9] E. Sornay-Rendu, S. Boutroy, F. Munoz, and P. D. Delmas, "Alterations of cortical and trabecular architecture are associated with fractures in postmenopausal women, partially independent of decreased BMD measured by DXA: the OFELY study," Journal of Bone and Mineral Research, vol. 22, no. 3, pp. 425-433, 2007.

[10] H. M. Frost, "The mechanostat: a proposed pathogenic mechanism of osteoporoses and the bone mass effects of mechanical and nonmechanical agents," Bone and Mineral, vol. 2, no. 2, pp. 73-85, 1987.

[11] J. Bernhardt, J. Chan, I. Nicola, and J. M. Collier, "Little therapy, little physical activity: rehabilitation within the first 14 days of organized stroke unit care," Journal of Rehabilitation Medicine, vol. 39, no. 1, pp. 43-48, 2007.

[12] J. Bernhardt, H. Dewey, A. Thrift, and G. Donnan, "Inactive and alone: physical activity within the first 14 days of acute stroke unit care," Stroke, vol. 35, no. 4, pp. 1005-1009, 2004.

[13] N. Baecker, A. Tomic, C. Mika et al., "Bone resorption is induced on the second day of bed rest: results of a controlled crossover trial," Journal of Applied Physiology, vol. 95, no. 3, pp. 977-982, 2003.

[14] P. Garnero, E. Hausherr, M. C. Chapuy et al., "Markers of bone resorption predict hip fracture in elderly women: the EPIDOS prospective study," Journal of Bone and Mineral Research, vol. 11, no. 10, pp. 1531-1538, 1996. 
[15] H. E. Berg, O. Eiken, L. Miklavcic, and I. B. Mekjavic, "Hip, thigh and calf muscle atrophy and bone loss after 5-week bedrest inactivity," European Journal of Applied Physiology, vol. 99, no. 3, pp. 283-289, 2007.

[16] M. J. Henry, J. A. Pasco, S. Korn, J. E. Gibson, M. A. Kotowicz, and G. C. Nicholson, "Bone mineral density reference ranges for Australian men: geelong osteoporosis study," Osteoporosis International, vol. 21, no. 6, pp. 909-917, 2010.

[17] G. Jones, T. Nguyen, P. Sambrook, P. J. Kelly, and J. A. Eisman, "Progressive loss of bone in the femoral neck in elderly people: longitudinal findings from the Dubbo osteoporosis epidemiology study," British Medical Journal, vol. 309, no. 6956, pp. 691-695, 1994.

[18] D. Clements, J. E. Compston, C. Evans, and W. D. Evans, "Bone loss in normal British women; A 5 year follow-up," British Journal of Radiology, vol. 66, no. 792, pp. 1134-1137, 1993.

[19] L. Jorgensen, B. K. Jacobsen, T. Wilsgaard, and J. H. Magnus, "Walking after stroke: does it matter? Changes in bone mineral density within the first 12 months after stroke. A longitudinal study," Osteoporosis International, vol. 11, no. 5, pp. 381-387, 2000.

[20] L. Jorgensen, N. J. Crabtree, J. Reeve, and B. K. Jacobsen, "Ambulatory level and asymmetrical weight bearing after stroke affects bone loss in the upper and lower part of the femoral neck differently: bone adaptation after decreased mechanical loading," Bone, vol. 27, no. 5, pp. 701-707, 2000.

[21] L. Jorgensen and B. K. Jacobsen, "Functional status of the paretic arm affects the loss of bone mineral in the proximal humerus after stroke: a 1-year prospective study," Calcified Tissue International, vol. 68, no. 1, pp. 11-15, 2001.

[22] M. Y. C. Pang, M. C. Ashe, and J. J. Eng, "Muscle weakness, spasticity and disuse contribute to demineralization and geometric changes in the radius following chronic stroke," Osteoporosis International, vol. 18, no. 9, pp. 1243-1252, 2007.

[23] M. Y. C. Pang, J. J. Eng, H. A. McKay, and A. S. Dawson, "Reduced hip bone mineral density is related to physical fitness and leg lean mass in ambulatory individuals with chronic stroke," Osteoporosis International, vol. 16, no. 12, pp. 1769 1779, 2005.

[24] M. C. Ashe, P. Fehling, J. J. Eng, K. M. Khan, and H. A. McKay, "Bone geometric response to chronic disuse following stroke: a pQCT study," Journal of Musculoskeletal Neuronal Interactions, vol. 6, no. 3, pp. 226-233, 2006.

[25] D. Bonaiuti, B. Shea, R. Iovine et al., "Exercise for preventing and treating osteoporosis in postmenopausal women," The Cochrane Library, no. 2, 2002.

[26] M. Martyn-St. James M. and S. Carroll, "High-intensity resistance training and postmenopausal bone loss: a meta-analysis," Osteoporosis International, vol. 17, no. 8, pp. 1225-1240, 2006.

[27] P. K. Myint, K. E. S. Poole, and E. A. Warburton, "Hip fractures after stroke and their prevention," QJM, vol. 100, no. 9, pp. 539-545, 2007.

[28] M. Martyn-St James and S. Carroll, "Meta-analysis of walking for preservation of bone mineral density in postmenopausal women," Bone, vol. 43, no. 3, pp. 521-531, 2008.

[29] C. J. Hamilton, V. J. D. Swan, and S. A. Jamal, "The effects of exercise and physical activity participation on bone mass and geometry in postmenopausal women: a systematic review of pQCT studies," Osteoporosis International, vol. 21, no. 1, pp. 11-23, 2010.

[30] D. de Kam, E. Smulders, V. Weerdesteyn, and B. C. M. SmitsEngelsman, "Exercise interventions to reduce fall-related fractures and their risk factors in individuals with low bone density: a systematic review of randomized controlled trials," Osteoporosis International, vol. 20, no. 12, pp. 2111-2125, 2009.

[31] M. Martyn-St James and S. Carroll, "A meta-analysis of impact exercise on postmenopausal bone loss: the case for mixed loading exercise programmes," British Journal of Sports Medicine, vol. 43, no. 12, pp. 898-908, 2009.

[32] A. Guadalupe-Grau, T. Fuentes, B. Guerra, and J. A. L. Calbet, "Exercise and bone mass in adults," Sports Medicine, vol. 39, no. 6, pp. 439-468, 2009.

[33] R. Nikander, H. Sievänen, A. Heinonen, R. M. Daly, K. UusiRasi, and P. Kannus, "Targeted exercise against osteoporosis: a systematic review and meta-analysis for optimising bone strength throughout life," BMC Medicine, vol. 8, p. 47, 2010.

[34] M. Martyn-St James and S. Carroll, "Effects of different impact exercise modalities on bone mineral density in premenopausal women: a meta-analysis," Journal of Bone and Mineral Metabolism, vol. 28, no. 3, pp. 251-267, 2010.

[35] K. Borschmann et al., "Stepping towards prevention of bone loss after stroke: a systematic review of the skeletal effects of physical activity after stroke," International Journal of Stroke. In press.

[36] Osteoporosis Australia, "Exercise and fracture prevention, a guide for GPs and health professionals," 2007, http:// www.osteoporosis.org.au/images/stories/documents/internal/ oa_exercise_gphp.pdf.

[37] R. F. Macko, F. Benvenuti, S. Stanhope et al., "Adaptive physical activity improves mobility function and quality of life in chronic hemiparesis," Journal of Rehabilitation Research and Development, vol. 45, no. 2, pp. 323-328, 2008.

[38] M. J. Lee, S. L. Kilbreath, M. F. Singh, B. Zeman, and G. M. Davis, "Effect of Progressive Resistance Training on Muscle Performance after Chronic Stroke," Medicine and Science in Sports and Exercise, vol. 42, no. 1, pp. 23-34, 2010.

[39] D. H. Saunders, C. A. Greig, G. E. Mead, and A. Young, "Physical fitness training for stroke patients," The Cochrane Library, no. $1,2009$.

[40] F. M. Ivey, A. S. Ryan, C. E. Hafer-Macko, A. P. Goldberg, and R. F. Macko, "Treadmill aerobic training improves glucose tolerance and indices of insulin sensitivity in disabled stroke survivors: a preliminary report," Stroke, vol. 38, no. 10, pp. 2752-2758, 2007.

[41] National Stroke Foundation, Clinical Guidelines for Stroke Management, National Stroke Foundation, Melbourne, Australia, 2010.

[42] M. Y. C. Pang, J. J. Eng, A. S. Dawson, H. A. McKay, and J. E. Harris, "A community-based fitness and mobility exercise program for older adults with chronic stroke: a randomized, controlled trial," Journal of the American Geriatrics Society, vol. 53, no. 10, pp. 1667-1674, 2005.

[43] N. F. Gordon, M. Gulanick, F. Costa et al., "Physical activity and exercise recommendations for stroke survivors," Circulation, vol. 109, no. 16, pp. 2031-2041, 2004.

[44] E. L. Miller, L. Murray, L. Richards et al., "Comprehensive overview of nursing and interdisciplinary rehabilitation care of the stroke patient: a scientific statement from the American heart association," Stroke, vol. 41, no. 10, pp. 2402-2448, 2010.

[45] Beijing Neurologist Club, BNC Practice Guidelines of Cerebrovascular Diseases, People Medical Publishing House, Beijing, China, 2002.

[46] A. Peeters, P. Cras, and S. Blecic, "Proposal of guidelines for acute stroke treatment and management," Acta Neurologica Belgica, vol. 102, no. 2, pp. 46-48, 2002. 
[47] P. Desfontaines, G. Vanhooren, A. Peeters, P. Laloux, and S. Blecic, "Proposal of guidelines for stroke units," Acta Neurologica Belgica, vol. 102, no. 2, pp. 49-52, 2002.

[48] Canadian Stroke Network and the Heart and Stroke Foundation of Canada and Canadian Stroke Strategy, Canadian Best Practice Recommendations for Stroke Care: 2006, Ottawa, Canada, 2006.

[49] Guidelines Writing Group, "Chinese acute ischaemic stroke management guideline," Chinese Clinical Journal of Neurology, vol. 43, no. 2, pp. 1-8, 2010.

[50] V. Demarin, A. Lovrenčić-Huzjan, Z. Trkanjec et al., "Recommendations for stroke management 2006 update," Acta Clinica Croatica, vol. 45, no. 3, pp. 219-285, 2006.

[51] The European Stroke Organization (ESO) Executive Committee and ESO Writing Committee, Guidelines for Management of Ischaemic Stroke and Transient Ischaemic Attack, 2008.

[52] The Stroke Prevention and Educational Awareness Diffusion (SPREAD) Collaboration, "The Italian guidelines for stroke prevention," Neurological Sciences, vol. 21, no. 1, pp. 5-12, 2000.

[53] Y. Shinohara and T. Yamaguchi, "Outline of the Japanese guidelines for the management of stroke 2004 and subsequent revision," International Journal of Stroke, vol. 3, no. 1, pp. 5562, 2008.

[54] National Collaborating Centre for Chronic Conditions, $\mathrm{Na}$ tional Clinical Guideline for Diagnosis and Initial Management of Acute Stroke and Transient Ischaemic Attack (TIA), Royal College of Physicians, London, UK, 2008.

[55] Norwegian Health Directorate, Norwegian National Guideline for Stroke, 2010.

[56] Nova Scotia Health, Nova Scotia Guidelines for Stroke Care, 2008.

[57] L. Brosseau, G. A. Wells, H. M. Finestone et al., "Ottawa panel evidence-based clinical practice guidelines for post-stroke rehabilitation," Topics in Stroke Rehabilitation, vol. 13, no. 2, pp. 1-269, 2006.

[58] R. P. S. van Peppen et al., "KNGF clinical practice guideline for physical therapy in patients with stroke. Review of the evidence," Nederlands Tijdscrift voor Fysiotherapie, vol. 114, no. 5, supplement, 2004.

[59] Scottish Intercollegiate Guidelines Network, "Management of patients with stroke: rehabilitation, prevention and management of complications, and discharge planning a national clinical guideline," NHS Quality Improvement Scotland, 2010.

[60] C. Best et al., Best Practice Guidance for the Development of Exercise after Stroke Services in Community Settings, The University of Edinburgh, Edinburgh, Scotland, 2010.

[61] Singapore Ministry of Health, "Stroke and transient ischaemic attacks assessment, investigation, immediate management and secondary prevention," 2009.

[62] A. Bryer, M. Connor, P. Haug et al., "South African guideline for management of ischaemic stroke and transient ischaemic attack 2010: a guideline from the South African Stroke Society (SASS) and the SASS Writing Committee," South African Medical Journal, vol. 100, no. 11, pp. 747-778, 2010.

[63] Stroke Foundation of New Zealand, "New Zealand clinical guidelines for stroke management 2010," 2010.

[64] Stroke Society of the Philippines, Guidelines for the Prevention, Treatment and Rehabilitation of Brain Attack, 2006.

[65] Swedish National Board of Health and Welfare, "National guidelines for stroke care in 2009-support for governance and management," 2009.

[66] Intercollegiate Stroke Working Party, National Clinical Guideline for Stroke, 3rd edition, 2008.
[67] The Management of Stroke Rehabilitation Working Group, Veterans' Affairs/ Department of Defence Clinical Practice Guideline for the Management of Stroke Rehabilitation, Version 2.0, 2010.

[68] M. M. S. James and S. Carroll, "Effects of different impact exercise modalities on bone mineral density in premenopausal women: a meta-analysis," Journal of Bone and Mineral Metabolism, vol. 28, no. 3, pp. 251-267, 2010.

[69] M. Y. C. Pang, M. C. Ashe, J. J. Eng, H. A. McKay, and A. S. Dawson, "A 19-week exercise program for people with chronic stroke enhances bone geometry at the tibia: a peripheral quantitative computed tomography study," Osteoporosis International, vol. 17, no. 11, pp. 1615-1625, 2006.

[70] M. E. Shimizu, F. Ishizaki, and S. Nakamura, "Results of a home exercise program for patients with osteoporosis resulting from neurological disorders," Hiroshima Journal of Medical Sciences, vol. 51, no. 1, pp. 15-22, 2002.

[71] M. Y. C. Pang and R. W. K. Lau, "The effects of treadmill exercise training on hip bone density and tibial bone geometry in stroke survivors: a pilot study," Neurorehabilitation and Neural Repair, vol. 24, no. 4, pp. 368-376, 2009.

[72] N. Venketasubramanian, K. H. Pwee, and C. P.L. Chen, "Singapore ministry of health clinical practice guidelines on stroke and transient ischemic attacks," International Journal of Stroke, vol. 6, no. 3, pp. 251-258, 2011.

[73] M. Y. C. Pang, J. J. Eng, A. S. Dawson, and S. Gylfadóttir, "The use of aerobic exercise training in improving aerobic capacity in individuals with stroke: a meta-analysis," Clinical Rehabilitation, vol. 20, no. 2, pp. 97-111, 2006.

[74] G. S. Beaupre and H. L. Lew, "Bone-density changes after stroke," American Journal of Physical Medicine and Rehabilitation, vol. 85, no. 5, pp. 464-472, 2006.

[75] T. Ikai, M. Uematsu, S. S. Eun, C. Kimura, C. Hasegawa, and S. Miyano, "Prevention of secondary osteoporosis postmenopause in hemiplegia," American Journal of Physical Medicine and Rehabilitation, vol. 80, no. 3, pp. 169-174, 2001.

[76] National Institute for Health and Clinical Excellence, The Guidelines Manual 2007, NICE, London, UK, 2007.

[77] A. Ramnemark, L. Nyberg, B. Borssén, T. Olsson, and Y. Gustafson, "Fractures after stroke," Osteoporosis International, vol. 8, no. 1, pp. 92-95, 1998.

[78] National Health and Medical Research Council, "NHMRC additional levels of evidence and grades for recommendations for developers of guidelines," 2010. 


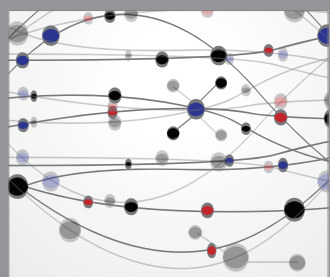

The Scientific World Journal
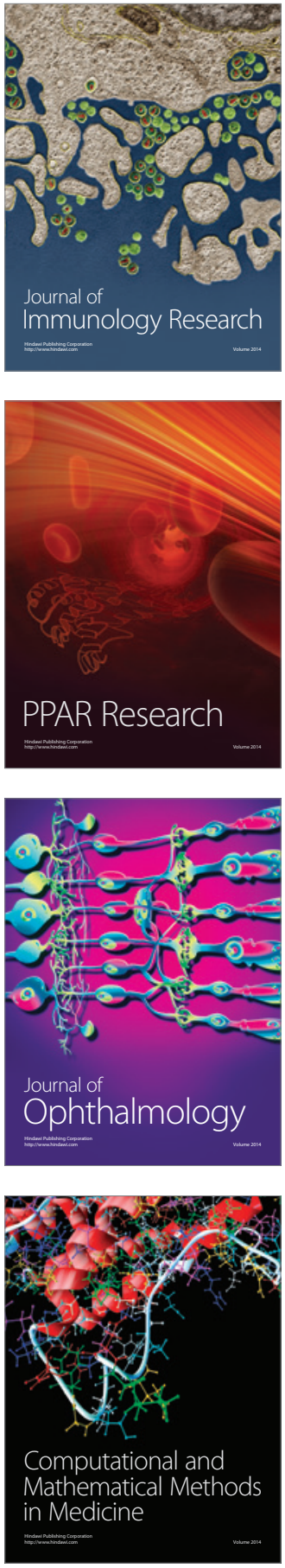

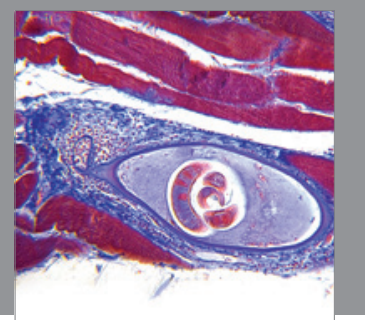

Gastroenterology

Research and Practice
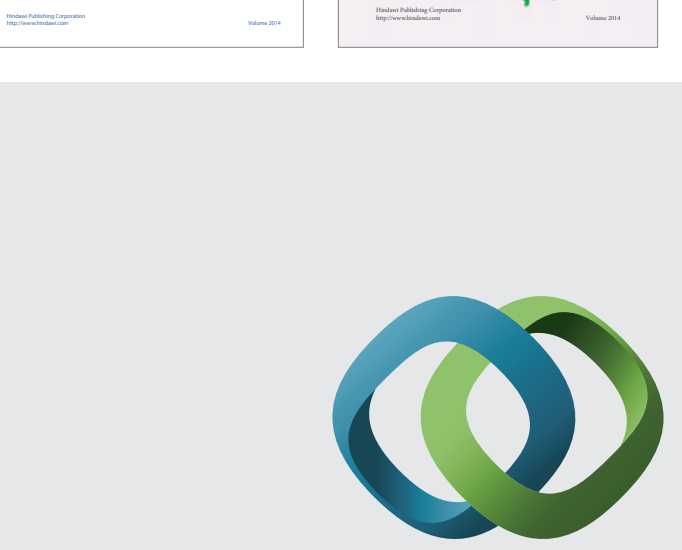

\section{Hindawi}

Submit your manuscripts at

http://www.hindawi.com
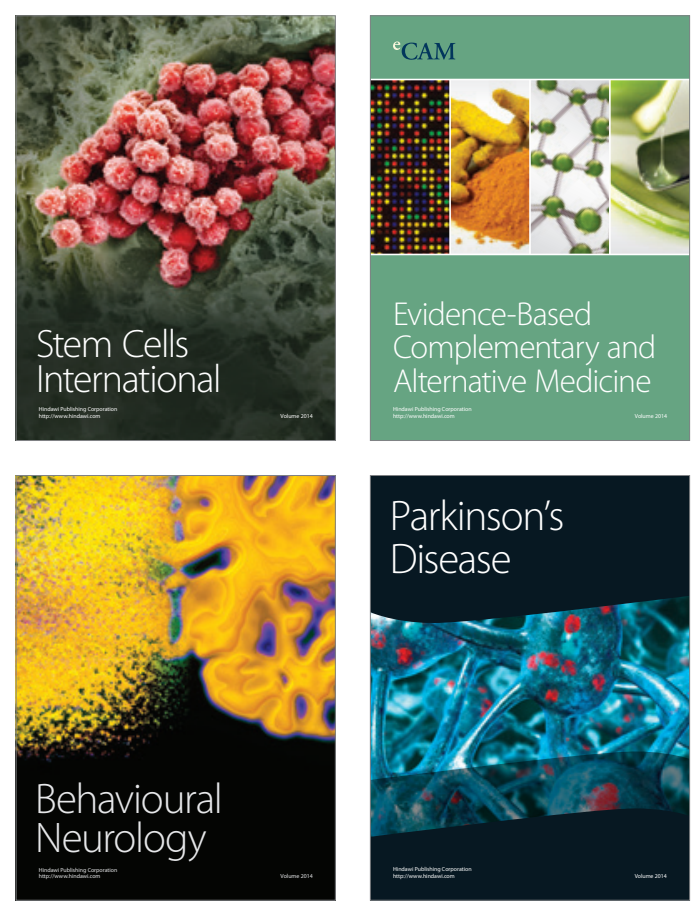

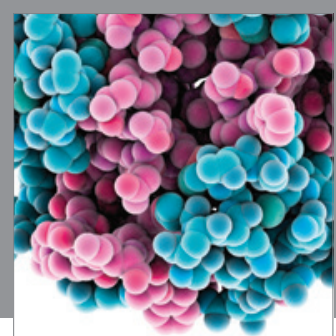

Journal of
Diabetes Research

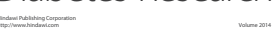

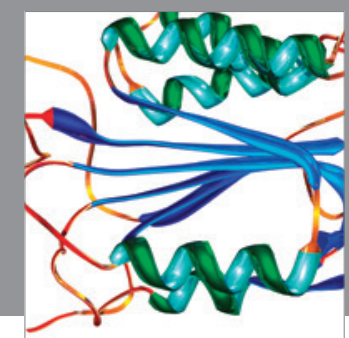

Disease Markers
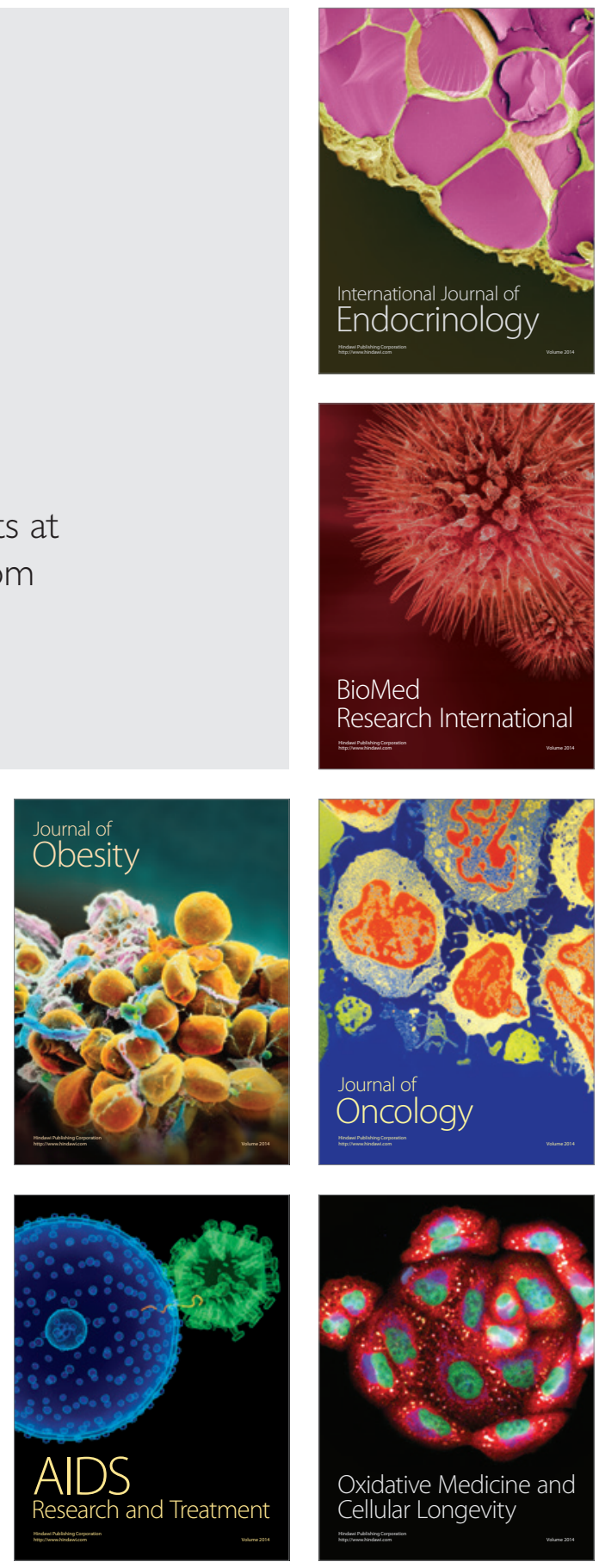